\title{
Monitoring of emerging drinking water disinfection by-products for microbial inactivation
}

\author{
S. Abbas ${ }^{1}$, I. Hashmi ${ }^{1}$, I. A. Qazi ${ }^{1}$, M. A. Awan ${ }^{1} \&$ H. Nasir ${ }^{2}$ \\ ${ }^{1}$ Institute of Environmental Sciences (IESE), \\ School of Civil and Environmental Engineering (SCEE), \\ National University of Sciences and Technology (NUST), \\ Islamabad, Pakistan \\ ${ }^{2}$ School of Chemical and Material Engineering (SCME), \\ National University of Sciences and Technology (NUST), \\ Islamabad, Pakistan
}

\begin{abstract}
Disinfection of water supplies is of paramount importance for the prevention of water borne diseases. Unfortunately, this leads to the formation of disinfection by-products. Currently, chlorine is the cheapest agent used to disinfect major drinking water supplies. The objective of the study was to report the occurrence of Total Trihalomethanes (TTHMs) in the distribution network system of the twin cities, Islamabad and Rawalpindi. At present, no significant data relating THMs have been reported in Pakistan. None of the DBPs are regulated in Pakistan and internationally it is required by law that the sum of four THMs does not exceed $80 \mu \mathrm{g} / \mathrm{L}$ with a frequency of sampling dependent on the population size. A simple and rapid method solid phase micro-extraction (SPME) was used for the extraction of TTHMs samples (Trichloromethane (Chloroform), Bromodichloromethane (BDCM), Dibromochloromethane (DBCM), Tribromomethane (bromoform). The water distribution network was monitored over a period of three months; samples were collected from thirty different sampling points. The concentration of the targeted compounds was analyzed using GC Gas Chromatography Shimadzu 2010 series coupled with electron capture detector. Samples were collected from different sampling sites including water filtration plants, overhead reservoir, underground storage tank and
\end{abstract}


consumer taps. The result of analysis showed the presence of THMs in $90 \%$ of drinking water samples collected after chlorination. The most commonly DBP encountered was chloroform at all sampling stations except 14, 15 and 18 . Results from the analysis indicated the presence of Trihalomethanes in the water sample collected from 27 stations. Only three sites met the standard value of $80 \mu \mathrm{g} / \mathrm{L}$. Poor budget allocation, sloppy governance and ageing infrastructure are some of the reasons for this.

Keywords: trihalomethanes, distribution network, disinfection byproducts, chlorination, gas chromatography, solid phase micro-extraction (SPME).

\section{Introduction}

Water quality assurance is currently an important issue at the local, national and international level. Thus, it is vitally important to appropriately manage and treat drinking water for the benefit of society. Drinking water disinfection is one of the major public health advances of the past century. Chemical disinfectants are effective for killing harmful microorganisms in drinking water, but they are also powerful oxidants, oxidizing the organic matter, anthropogenic contaminants, and bromide/iodide naturally present in most source waters (rivers, lakes, and many ground waters). Chlorination has been in continuous use for disinfection since early 1900s against several water borne diseases such as cholera, typhoid, dysentery, hepatitis etc. Chlorine is used in water, an essential step in delivering safe drinking water and protecting public health.

Chlorine is by far the most commonly used and inexpensive disinfectant in all regions of the world (Chowdhury et al. [1]). However, it was found in 1972 by Rook [2] that chlorination can lead to formation of potentially harmful chemical compounds formed unintentionally when chlorine and other disinfectants react with natural organic matter (NOM) and/ or bromide/iodide present in water (Bischel and von Gunten [3]). Chlorine, ozone, chlorine dioxide, and chloramines are the most common disinfectants in use today; each produces its own suite of DBPs in drinking water, with overlapping constituents.

There are two major types of chlorinated disinfection byproducts trihalomethanes (THMs) and Haloacetic acids (HAAs). Trihalomethanes have further categorized into four species chloroform $\left(\mathrm{CHCl}_{3}\right)$, bromodichloromethanes $\left(\mathrm{CHBrCl}_{2}\right)$, dibromochloromethane $\left(\mathrm{CHBr}_{2} \mathrm{Cl}\right)$ and bromoform $\left(\mathrm{CHBr}_{3}\right)$. Bull et al. [4] investigated that these compounds formed are not only mutagenic but also potential carcinogenic. Many studies indicate connection between cancer and exposure to THMs-contaminated potable water (Goi et al. [5]). The nature of chlorinated disinfection byproducts (CDBPs) formed depends on the amount and the chemical composition of organic species originally present. Number of other factors such as temperature, $\mathrm{pH}$, chlorine dose, retention time and amount of organic matter present also affect formation of chlorinated disinfection byproducts (CDBPs) in water.

Most developed nations have published regulations or guidelines to control DBPs and minimize consumers' exposure to potentially hazardous chemicals while maintaining adequate disinfection and control of targeted pathogens. In 30 
years since the THMs were identified as DBPs in drinking water, significant research efforts have been directed toward increasing our understanding of DBP formation, occurrence, and health effects. Although more than 600 DBPs have been reported in the literature, only a small number has been assessed in either quantitative occurrence or health-effects studies. The maximum contaminant levels (MCL) currently regulated by the USEPA for total THM and total HAA are $80 \mu \mathrm{g} / 1$ and $60 \mu \mathrm{g} / 1$ respectively (Richardson [6], Serrano and Gallego [7]). In Australia, Spain and Italy and Germany the maximum allowable contaminant levels in drinking water standards for total THMs were 250, 100, 30 and $10 \mu \mathrm{g} / \mathrm{l}$, respectively (Pavelic et al. [8], Sorlini and Collivignarelli [9]). So it is important to regulate and monitor the formation of THMs with the view to ensure the compliance of the guidelines set.

There are several analytical methods for the analysis of THMs such as solid phase microextraction (SPME), liquid-liquid extraction, static headspace technique and many others (Kuran and Sojak [10], Van Langenhove [11]). Among all these techniques SPME is the latest, sensitive and most convenient technique for the analysis of THMs.

Currently, no significant study is being carried out in Pakistan on THMs. This study is aimed at analysing the pollutant concentration in drinking water of the twin cities Islamabad and Rawalpindi.

\section{Material and methods}

\subsection{Chemicals and standards}

Chloroform $\left(\mathrm{CHCl}_{3}\right)$, bromodichloromethanes $\left(\mathrm{CHBrCl}_{2}\right)$, dibromochloromethane $\left(\mathrm{CHBr}_{2} \mathrm{Cl}\right)$ and bromoform $\left(\mathrm{CHBr}_{3}\right)$ were purchased from Dr. Ehrenstrofer (Germany). A standard stock solution of individual THMs were prepared by mixing $10 \mu \mathrm{L}$ of the standard analyte in $100 \mathrm{~mL}$ GC-grade methanol and were stored in sealed glass bottles at $4^{\circ} \mathrm{C}$.

\subsection{DBP sample collection}

Samples were collected from (i) underground storage tanks (ii) consumer taps and (iii) overhead reservoirs. All the samples were collected in triplicates. Measurement of $\mathrm{pH}$, temperature and residual chlorine were carried out in the field as mentioned in Standard methods for the examination of water and wastewater [12]. Other measurements were done in laboratory. Samples vials quenched with sodium thiosulfate $(10 \mathrm{mg}$ for $10 \mathrm{~mL}$ of sample) were used fully filled with water leaving no headspace.

\subsection{DBP analysis}

THMs concentration was measured with a GC/ECD equipped with fused silica capillary column. For sample extraction SPME technique was used using supleco cat. No.57344-U manual solid-phase microextraction fibre assembly fitted with a $75 \mu \mathrm{m}$ (Car PDMS) fibre. Fibre was first conditioned at $280^{\circ} \mathrm{C}$ for $1 \mathrm{~h}$ before 
use. All the samples were analyzed within 2 weeks of collection following USEPA method 551.1 [13]. Samples for analysis were collected in $40 \mathrm{~mL}$ vial. Extraction was performed with fibre immersed in the headspace for extraction for $10-15 \mathrm{~min}$ at $25^{\circ} \mathrm{C}$. Two micro litres of the THMs extracts were analyzed. Procedural calibrations were developed using THMs (chloroform, bromodichoromethane, dibromochloromethane, bromoform) standards. Further details of the experimental procedures and calibrations can be found elsewhere (USEPA [14]). The functioning condition for GC is cited in Table 1.

Table 1: Gas chromatographic conditions for THMs analysis.

\begin{tabular}{|c|c|}
\hline Parameters & Values \\
\hline Carrier gas & Helium \\
\hline Carrier gas flow & $5 \mathrm{~mL} / \mathrm{min}$ \\
\hline 1. Injector & $48.2 \mathrm{Kpa}$ \\
\hline Pressure & $200^{\circ} \mathrm{C}$ \\
\hline Temperature & Split \\
\hline Injection mode & $24.4 \mathrm{~cm} / \mathrm{sec}$ \\
\hline Linear velocity & 90.0 \\
\hline Split ratio & \\
\hline 2. Column & $50^{\circ} \mathrm{C}$ \\
\hline Initial temperature & $200^{\circ} \mathrm{C}$ \\
\hline Final temperature & $220^{\circ} \mathrm{C}$ \\
\hline 3. Detector & \\
\hline Temperature & \\
\hline
\end{tabular}

\section{Results and discussion}

Drinking water from 30 different locations across the twin cities was analyzed to define typical concentrations of target DBPs. This study involved the participation and cooperation of water authorities of twin cities such as Capital Development Authority (CDA). All analytes were quantified using the peak area ratios relative to the standard analytes bases on single point calibration from stock solutions (Cho et al. [15]). Response factors for the stock solution standard analytes were calculated using single point calibration against their concentration of $11.9,1.9,2.41$ and $260 \mu \mathrm{g} / \mathrm{L}$ and are shown in Table 2. 
Table 2: Concentration, retention times and peak areas of stock solutions of standard analytes.

\begin{tabular}{|c|c|c|c|c|}
\hline Analyte & $\begin{array}{c}\text { Concentrations } \\
\mu \mathrm{g} / \mathrm{L}\end{array}$ & $\begin{array}{c}\text { Retention } \\
\text { time } \\
(\mathrm{min})\end{array}$ & Peak area & $\begin{array}{c}\text { RSD } \\
(\%)\end{array}$ \\
\hline Chloroform & 11.93 & 4.17 & $3989.2 \pm 311$ & 7.7 \\
\hline Bromodichloromethane & 1.98 & 5.36 & $6396.6 \pm 438$ & 6.8 \\
\hline Dibromochloromethane & 2.41 & 6.71 & $4921.8 \pm 437$ & 8.8 \\
\hline Bromoform & 260 & 7.02 & $41763 \pm 4736$ & 11.3 \\
\hline
\end{tabular}

Figure 1 represents the chromatogram obtained from SPME of standard stock trihalomethanes mixture at $25^{\circ} \mathrm{C}$ and also signifies the relationship between retention times and peak areas of stock solutions of standard analytes. Exposure and desorption time is an important parameter to accomplish distribution equilibrium of analytes between fibre and sample. Extraction and desorption time was 15 and 10 minutes respectively, while the desorption temperature was $200^{\circ} \mathrm{C}$.

It is well known that the interaction time of the fibre with the sample is a very important parameter; it influences the extraction recovery significantly. Four different extraction times were studied (8, 10, 15, $20 \mathrm{~min})$. The results showed that 15 min extraction time achieved the best extraction recovery and best reproducibility (Figure 2).

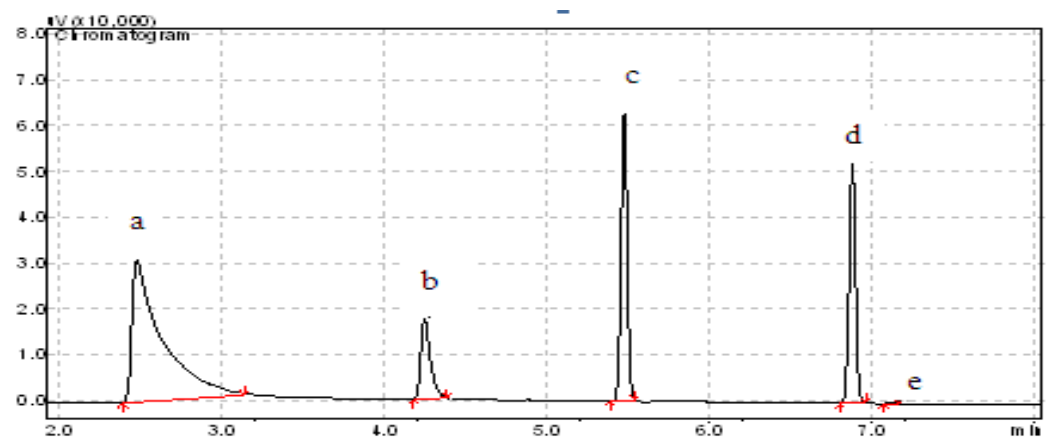

Figure 1: Chromatogram representing the retention time and sequence of $\begin{array}{lll}\text { standard analytes. (a) methanol, (b) chloroform, } & \text { (c) }\end{array}$ $\begin{array}{ll}\text { (c) bromodichloromethane, } & \text { (d) dibromochloromethane, }\end{array}$ (e) bromoform.

Samples were analyzed using optimized SPME and GC conditions. The proficiency of this extraction and concentration method is affected by multiple factors, including flow rate and the type of sorbent. Almost $95 \%$ samples were contaminated with THMs. Chloroform was found to be maximum in all samples 


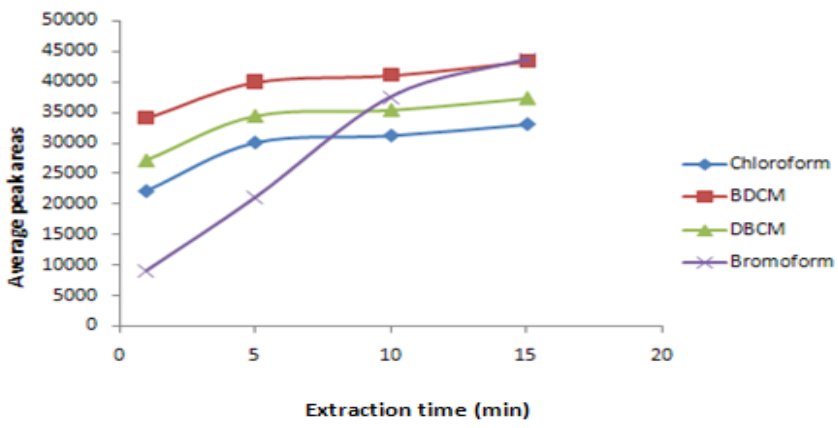

Figure 2: $\quad$ Maximum peak area at 15 min for all standard analytes.

from entire drinking water supply network i.e., underground tank, overhead reservoir and filtration plants. Chloroform was comparatively lower in concentration in underground tank and sampling station 14. Concentration of TTHMs ranged from 44.51 to 595.86 at different sampling station. The potential reason for contamination at different point is presence of natural organic matter. Trihalomethanes formation occurs when chlorine is added to such water sources. Speciation of THMs can vary conditional on the nature of the source water.

Figure 3 signifies the chromatogram acquired from drinking water sample of sampling station 9 as it had the maximum concentration of TTHMs. Out of 30 sampling sites only 3 sites met the US-EPA drinking water quality standard values, whereas remaining 27 sites were exceeding the standard value of $80 \mu \mathrm{g} / \mathrm{L}$.

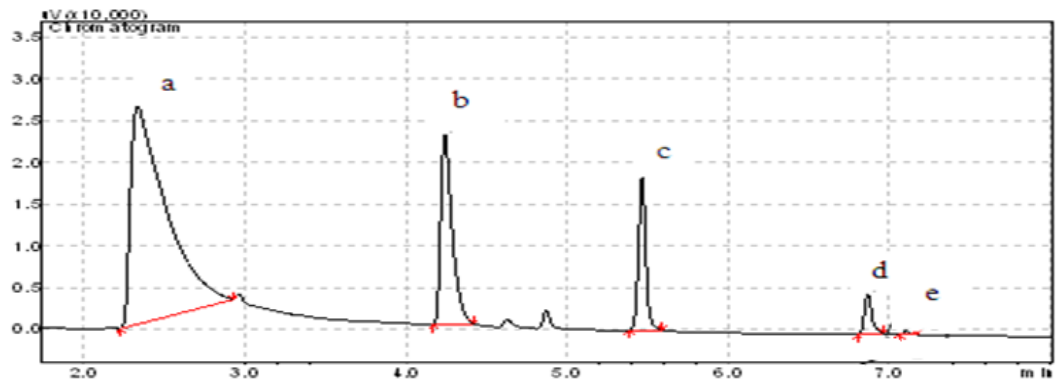

Figure 3: $\quad$ Chromatogram of sampling station 9. 
Table 3: $\quad$ Concentration of THMs $(\mu \mathrm{g} / \mathrm{L})$.

\begin{tabular}{|c|c|c|c|c|c|}
\hline Sr.no & $\begin{array}{c}\text { Chloroform } \\
\mathrm{CHCl}_{3}\end{array}$ & $\begin{array}{c}\text { DBCM } \\
\mathrm{CHClBr}_{2}\end{array}$ & $\begin{array}{c}\mathrm{BDCM} \\
\mathrm{CHCl}_{2} \mathrm{Br}\end{array}$ & $\begin{array}{c}\text { Bromoform } \\
\mathrm{CHBr}_{3}\end{array}$ & TTHMs \\
\hline Station 1 & 105 & 6.55 & 9.15 & BDL & 120.7 \\
\hline Station 2 & 150.04 & 7.4 & 12.4 & BDL & 169.84 \\
\hline Station 3 & 321 & 9.6 & 16.88 & 7.78 & 355.26 \\
\hline Station 4 & 360.59 & 2.22 & 9.95 & BDL & 387.47 \\
\hline Station 5 & 137 & 1.55 & 3.83 & BDL & 142.38 \\
\hline Station 6 & 106.7 & 4.84 & 8.66 & BDL & 120.2 \\
\hline Station 7 & 193.75 & 1.45 & 8.5 & BDL & 203.7 \\
\hline Station 8 & 295 & 2.75 & 15.45 & BDL & 313.2 \\
\hline Station 9 & 575.88 & 1.59 & 15.16 & 3.11 & 595.86 \\
\hline Station 10 & 280.22 & 15.81 & 22.44 & BDL & 318.47 \\
\hline Station 11 & 355 & 1.65 & 8.11 & BDL & 364.76 \\
\hline Station 12 & 96 & 3.67 & 7.98 & BDL & 107.65 \\
\hline Station 13 & 314 & 1.09 & 22.09 & BDL & 337.18 \\
\hline Station 14 & 23.87 & BDL & 0.55 & BDL & 24.42 \\
\hline Station 15 & 55.66 & 1.84 & 3 & BDL & 60.5 \\
\hline Station 16 & 171.13 & 5.96 & 7.83 & BDL & 184.92 \\
\hline Station 17 & 130.43 & BDL & 2.09 & BDL & 132.52 \\
\hline Station 18 & 40.69 & 1.84 & 1.98 & BDL & 44.51 \\
\hline Station 19 & 232.4 & 13.53 & 33.21 & 4.11 & 283.25 \\
\hline Station 20 & 417.66 & 1.11 & 10.11 & BDL & 428.88 \\
\hline Station 21 & 100.7 & 4.93 & 7.11 & BDL & 112.74 \\
\hline Station 22 & 144.5 & 0.69 & 5.64 & BDL & 150.83 \\
\hline Station 23 & 103.56 & 3.14 & 7.87 & BDL & 114.57 \\
\hline Station 24 & 247.1 & 13.24 & 13.98 & BDL & 274.32 \\
\hline Station 25 & 258 & 17.55 & 18.64 & BDL & 294.19 \\
\hline Station 26 & 172 & 7.32 & 10.65 & BDL & 189.97 \\
\hline Station 27 & 271 & 18.21 & 23.65 & 5.72 & 189.97 \\
\hline Station 28 & 382.01 & 1.99 & 14.02 & BDL & 398.02 \\
\hline Station 29 & 415.06 & 2.11 & 14.09 & BDL & 431.26 \\
\hline Station 30 & 182 & 9.01 & 16.21 & BDL & 207.22 \\
\hline BDL: Below & & & & \\
\hline
\end{tabular}

BDL: Below detectable limit.

\section{Conclusion}

This study compared DBPs formation in different parts of the twin cities. The data showed that most of the samples were contaminated. Further investigation is suggested to better understand the formation of DBPs as the levels found were significant. SPME technique was successfully applied to determine the trihalomethanes in drinking water. Unfortunately almost 95\% samples were contaminated with THMs. In such cases where DBP values are closely approached 
or exceeded, water authorities need to review water treatment practices with view to improve the removal of organics form the water sources prior to disinfection, using alternative disinfectants and reducing water age in distribution system. The potential risks associated with DBPs are still largely unknown, although some toxicological and epidemiological studies provide some information. More research is needed to determine the risk associated with DBPs.

As the DBPs issue increases in momentum in Pakistan, the emphasis will be to minimize DBP formation whilst maintaining a microbiologically safe product. Undoubtedly, this will present a number of operational challenges for local water authorities.

\section{References}

[1] Chowdhury, S., Champagne, P. \& Husain, T., Fuzzy approach for selection of drinking water disinfectants, J Water SRT-Aqua, 56 (2), pp. 75-93, 2007.

[2] Rook, J.J., Formation of haloforms during chlorination of natural waters. Journal of the Society for Water Treatment and Examination, 23, pp. 234243, 1974.

[3] Bischel, Y. \& von Gunten, U., Formation of iodinated trihalomethanes during disinfection and oxidation of iodide containing waters. Environmental Science and Technology, 34 (13), pp. 2784-2791, 2000a.

[4] Bull, R.J., Krasner, S.W., Daniel, P.A. \& Bull, R.D., Health effects and occurrence of disinfection byproducts; American Water Works Association Research Foundation and American Water Works Association, Denver, CO, USA, 2001.

[5] Goi, D., Tubaro, F., Barbone, F., Dolcetti, G \& Bontempelli, G., Evaluation of chlorinated byproducts in drinking waters of central Friuli (Italy). Ann Chem, 95 (9-10), pp. 617-627, 2005.

[6] Richardson, S. D., Disinfection byproducts and other emerging contaminants drinking water. Trends in Analytical Chemistry, 22(10), pp. 666-684, 2003.

[7] Serrano, A. \& Gallego, M., Rapid determination of total trihalomethanes index in drinking water. Journal of Chromatography A, 1154, pp. 26-33, 2007.

[8] Pavelic, P., Nicholson, B.C., Dillon, P.J. \&Barry, K.E., Fate of disinfection byproducts in ground water during aquifer storage and recovery with reclaimed water. Journal of Contaminant Hydrology, 77, pp. 119-141, 2005.

[9] Sorlini, S. \& Collivignarelli, C., Trihalomethanes formation during chemical oxidation with chlorine, chlorine dioxide and ozone of ten Italian natural water. Desalination, 176, pp. 103-111, 2005.

[10] Kuran, P. \& Sojak, L., Environmental analysis of volatile organic compounds in water and sediments by gas chromatography. Journal of Chromatography A, 733, pp. 119-141, 1996.

[11] Van Langenhove, D.H.J., Anthropogenic volatile organic compounds in ambient air and natural waters: a review on recent developments of 
analytical methodology. Performance and interpretation of field measurements. Journal of Chromatography A, 843, pp. 163-177, 1999.

[12] APHA (American Public Health Association). Standard methods for the examination of water and wastewater $\left(22^{\text {nd }}\right.$ ed.). Washington, DC, USA, 2005.

[13] USEPA., Determination of chlorinated disinfection by-products and chlorinated solvents in drinking water by liquid-liquid extraction and gas chromatography with electron capture detection; Environmental Monitoring Systems Laboratory Office of Research and Development, Method 551.1, 1995.

[14] USEPA., Determination of Haloacetic acids in drinking water by liquidliquid extraction and gas chromatography with electron capture detection; National Exposure Research Laboratory Office of Research and Development, Method 552.2, 1995.

[15] Cho, D., Kong, S. H. \&Oh, S. G., Analysis of trihalomethanes in drinking water using headspace-SPME technique with gas chromatography. Water Research, 37 (2), pp. 402-408, 2003. 